\title{
Online and other ICT Applications for Cognitive Training and Assessment
}

\author{
http://dx.doi.org/10.3991/ijoe.v11i2.4360 \\ Maria Karyotaki, Athanasios Drigas \\ N.C.S.R. 'Demokritos', Athens, Greece
}

\begin{abstract}
Cognitive training and assessment refers to ICTs and their relation with students, students with learning disabilities and adults with dementia. This article revises on contemporary research concerning ICTs effectiveness on the training and assessment of attention, memory and executive control functions. Artificial intelligence seems to hold a significant role in the field of cognitive training and rehabilitation as its adaptability and interactivity, enhance users' motivation and involvement. Moreover, artificial intelligence in combination with other applications provides the means for holistic and cost-effective cognitive interventions through its integrative information processes. Evidently, educators and therapists should advocate of improvements in the engineering features of the applications as well as they should, themselves, expand the implementation of the aforementioned technological innovations in favour of the users' cognition.
\end{abstract}

Index Terms-cognitive skills, cognitive interventions, online applications, online assessment $\&$ training.

\section{INTRODUCTION}

Drigas et al. made a review study on the integration of ICTs in the battle against memory deficits. Working memory performance may be measured either through online or stand-on neuropsychological tests, whereas video games may improve working memory capacity and performance. Long-term memory impairments may be dealt with computer programs related to individuals' personalised training and assessment as well as through artificial intelligence techniques for supporting the elderly and sufferers from severe memory impairments.

Howard-Jones et al. made a review analysis on the common scientific field between neurosciences and technology-enhanced learning in an attempt to induce students' learning potential. According to recent studies, early years' literacy and numeracy as well as creativity and collaborative and social skills may be strongly benefited from technology, either through adaptive educational programs, online platforms, free web-based applications or artificial collaborators. Games have a pivotal role in students' learning and motivation, thus engage neuroscientists and educators in harnessing the beneficial effects of technology.

Weng et al. revised research studies on cognitive skillsbased computer-assisted instruction for students with disabilities on account of their learning potential and design features. Synthesized findings of the previous studies verified of the fact that computer technology can largely serve as learning boosters for students with disabilities, although insufficient illustration on design features of the computer-assisted instruction and lack of an in-depth analysis on a specific type of disability, limited studies' overall consistency and cohesiveness. Tablet computers offer contemporary means for performing further studies in the field of cognitive skills-based computer-assisted instruction for students with disabilities.

Fletcher-Watson revised on computer-assisted learning for people with autism spectrum disorder. Evidence suggests that direct and immediate feedback of programs, personalized reinforcement as well as the provision of complementary support by a teacher lead to technological impact expansion. Furthermore, touch screen and tangible hardware may be of assistance in order to facilitate the use of web, online gaming and virtual worlds for enhancing autistic's community both social, life and academic learning skills. The adaption of artificial intelligence elements in the design and implementation of computer-assisted learning accompanied with the evaluation of its direct and indirect effects on autistics should be thoroughly looked into in future studies.

Aresti-Bartolome et al. reviewed recent research on $\mathrm{Au}$ tistic Spectrum Disorder sufferers in relevance to their assessment and therapy through ICTs. Virtual reality applications, applications designed for computers, tablets or mobiles, telehealth systems and robots were the technologies constituting the background of the interventions. Technologies were further classified to communication and interaction, social learning and imitation skills as well as other associated conditions in Autism. In conclusion, virtual reality applications offer the opportunities for $\mathrm{Au}-$ tistic individuals to improve their cognitive and social skills through realistic situations, whereas applications for computers, tablets or mobiles can be consistent training tools as long as they are accompanied by human assistance. Moreover, telehealth systems may be useful as an instant communication path with specialists, for both of the counterparts: people with Autistic Spectrum Disorders and their family members. Finally, robots with voice technology can be substantially important in the acquisition of Autistic people's social skills. Nevertheless, the aforementioned technologies have to be examined thoroughly as to the transferred skills in Autistic individuals' real life. In addition, taking in mind individuals' personal differences should be a priority in the design of innovative technologies, for example through implementing adaptive systems or through the combination of various technologies in the same system.

Siberski et al. made a study on intellectually and developmental disabled adults' computer-based cognitive training. Results showed positive trends in the target group's cognitive enhancement with special focus on the beneficial role of low complexity computer programs, such as 
computer games, on their motivation, attention and time on task.

Singh et al. refers to some basic cognitive skills, such as attention, memory, language, visual and spatial processing, logic and reasoning, interpersonal and intrapersonal skills in order to address to the issues of cognitive enhancement. Education, enriched environment and mental training, including video games, symbolic programs, expert systems and search agents may lead to specific improvements in humans' cognitive task performance.

Lauriks et al. explore current trends on ICT-based assistance and support for people with dementia and their carers. Stand-on and web-based applications provide the technological means for stimulating patients' memory and enhance carers' emotional state in addition to mobiles and GPS devices, offering patients' and their relatives' instant communication and feelings of safety and security. Advanced research should focus on integrated, personalized systems regarding the monitoring of biological functions as well as behavioural and psychological changes occurring in people suffering from dementia.

Koldrack et al. review Alzheimer patients' assistive technologies for cognition (ATC) and mobility to enhance individuals' autonomy and safety. Current dynamically adaptive systems, such as reminding, micro-prompting, navigation, storing and displaying, alerting or distraction systems integrate individuals' with dementia social needs and cognitive abilities through their multi-modal operation. Such systems adapt to patients' disease progress, beginning from the early stages until the caregiver takes over, aiming at maximizing users' assistive effect, personalization and ease of use.

\section{ON LINE-WEB}

Petchtone et al. examined the validity of a web-based learning environment model aiming at the improvement of undergraduate students' cognitive skills and critical thinking. More specifically, the design principles of the model as well as its usability and effectiveness were found consistent and congruent with the enhancement of students' cognitive skills and critical thinking.

Lin et al. analyze cognitive processes in problemsolving activities through the integration of Facebook discussions and simulation-based teaching software. The results of the study indicated diverse and continuous cognitive processes taking place, such as remembering, understanding, applying and analyzing. Students' high-level cognitive processing can be reached through social knowledge construction computer-aided tools, such as concept-mapping tools accompanied by the instructors' task design and in-task support.

Howard-Jones et al. structured the design of a webbased application, called "zTP", which shed light on the potential importance of the teacher scaffolding learning in addition to students' gaming their score. Findings of the study revealed developers' and classroom stakeholders' optimal interrelationship in the classroom.

Jelcic et al. point at the effects of lexical-semantic stimulation through videoconferencing on Alzheimer patients' global cognition, language abilities, verbal and nonverbal related memory domains, attention and executive functions as well as visual-spatial abilities. Cognitive stimulation treatment through teleconference seems to be less efficient on memory abilities than face to face treatment, although in both cases global cognitive performance as well as language abilities improved.

Riegler et al. adopted an online treatment, the Military On-Line Problem Solving Videophone Intervention (MOPS-VI) for improving cognitive functioning in veterans with mild traumatic brain injury (TBI) through the incorporation of web-based modules and videophones with a speech-language pathologist. The MOPS-VI intervention was found beneficial for veterans recovering from mild TBI in terms of its positive cognitive outcomes and its briefer therapy, compared to standard office-based treatments.

Curcic introduce the Big6 Skills model as a scaffold aimed to improve seventh and eighth grade students' with learning disabilities literacy skills, such as information problem solving and writing from multiple we-based sources. Overall, the treatment group improved in their text length and organization quality. Further research is needed into the relation between the nature of task, students' motivation and performance.

Campbell et al. elaborate on the use of ICTs and especially the web in constructivist and inquiry-based learning, which reinforces students' communication and collaboration. Cyber-enabled resources, such as the open source, modular, extendable platform called OpenSimulator 3D Application Server with customizable terrain, weather and physics as well as several databases and software, such as the 3-D bar mapping with Google Earth can be used as cognitive tools available for hands-on experimentation and observation in biology and science classrooms.

\section{MOBILES}

Chen et al. studied on the different text display types of mobiles and their effects on learners' reading comprehension, sustained attention and cognitive load. Experimental results showed that the mixed text display type improved reading comprehension in mobile reading contexts when the reader was sited and kept a constant speed of reading. Nevertheless individuals' personal reading speed did not always match to the scrolling speed of the mobile text display, thus augmenting readers' extraneous cognitive load. In other words, readers' experiencing appropriate cognitive load through differentiated text scrolling speeds is a determining factor in promoting mobile active reading.

Brouillette et al. shed light on the use of an innovative smartphone-based application for the assessment of cognitive function in the elderly. The aforementioned application was found to be a reliable and valid measure of processing speed and attention in the elderly, although the relatively small screen of the smartphone should better be replaced by a tablet device, which combines both larger screen and higher computing capacity. Furthermore, such smartphones or tablet-based applications may well be a useful tool for mastering geriatric populations' health interventions through real-time monitoring, assessment and support.

\section{PC-BASED APPLICATIONS}

Gabriele et al. incorporated a Robotics-based learning approach to develop adult students' cognitive/metacognitive skills. Researchers deployed a Robotics kit in combination with tasks that required students' develop- 
PAPER

ment of programming strategies in order to build and control the robot's behaviour. Results of the study depict students' acquired abilities to analyze problems and select only the relevant information for the task solution as well as the stimulation of their problem solving and creative thinking skills. Finally, students found this project-based learning approach quite challenging and sociable.

Packiam Alloway et al. used a computerized and standardized tool, the Automated Working Memory Assessment (AWMA) to measure individuals' with Attention Deficit Hyperactivity Disorder (ADHD) and individuals' with specific language impairment (SLI) respective working memory performance in conjunction with specific cognitive skills. Findings of the study suggest that in both categories, verbal skills predict verbal-based academic tests as compared to visuo-spatial skills predicting, likewise, domain-specific academic tests. However, working memory is differentially linked to learning in ADHD and SLI without co-morbidity. ADHD participants performed better in some tasks of verbal abilities, whereas children with SLI had relative strengths in some nonverbal tasks. Therefore, in both cases emphasis should be placed on supporting difficulties in specific cognitive domains so as to come forth with specific learning gains.

Vugs et al. investigated on working memory performance and executive function behaviors in young children with specific language impairment (SLI) by using the validated and standardized test of Automated Working Memory Assessment. The SLI group had a serious lack in verbal and visuospatial memory as well as in executive and attentional control functions. Present findings indicate the importance of creating detailed profiles of the strengths and weaknesses of these children in order to design more personalized learning interventions through the adoption of simple visual information strategies.

Rute-Pérez et al. present PESCO, a series of computerized and standardized tests as an open-software application for cognitive evaluation and stimulation of the elderly. The aforementioned modules proved valid in terms of cognitive status assessment as well as in the improvement of the aging population's attention, working memory and planning skills. In continuance to current research, opensource virtual and augmentative reality software, which is called VIRTRA-EL (Virtual Training for the Elderly) is currently being developed to offer the means for real-time supervision and communication between the elderly and their carers.

Johnson et al. introduce the Social Annotation ModelLearning System (SAM-LS) created to develop students' reading comprehension, critical thinking and metacognitive skills through the appropriate implementation of social annotation technology. The study results intensified of the key role of students' collaborating with one another while working with the tool in regards to the formers' basic comprehension and meta-cognition effect. Further steps ahead suggest scrutinizing changes in students' performance in an attempt to advance design and implementation process of the technology tool, thereby inducing its effectiveness.

Demiris et al. introduce an informatics platform that integrates physiological, functional, cognitive, mental, spiritual and social data in order to assess and visualize of older adults' wellness. The researchers' pilot study verified of its utility and accessibility in addition to creating a holistic profile of older adults' diverse and complex needs. Studies should broaden their research field in community based informatics platforms to provide more personalized, accessible and holistic health care services for older adults.

Rocha Dores et al. present virtual reality technology in the neuropsychological assessment and rehabilitation of people with executive dysfunction due to Acquired Brain Injury (ABI). The main advantage of the ComputerAssisted Rehabilitation Program - Virtual Reality (CARPVR) stands in its applicability and usability for it can simulate realistic experiences from distance as if the patient could live his everyday life. This application is immersive and interactive, thus growing patients' motivation to take part in the rehabilitation process. It is worthy noticing that virtual reality does not substitute therapists' role in the program, as the latest are the coordinators of the interventions aiming to provide a holistic approach in patients' treatment.

\section{GAMES}

Lee et al. argue that while attention, memory and executive control functions are substantially improved while playing video games, any training/learning program should be largely scrutinized in regards to generalizing on its brain-mind-behavior effects, assisted by neurofeedback interaction and formative assessment practices originating in ICT engineering.

Lee et al. recommend an evaluation method concerning the potential cognitive and emotional effects of a walking tangible game. The experiment resulted in the need to perform long term research in the aforementioned field by placing extra emphasis on human cognitive components in setting clearly defined stimuli on experimental tasks. Serious game design effectiveness depends largely on the participating group's precise classification as well as on defining the most adequate characteristics on account of the application.

Frutos-Pascual et al. point out the role of biofeedback and serious games techniques as part of a validation protocol, succeeding a cognitive rehabilitation program for children with ADHD. The aforementioned validation protocol should hence be adjusted to the respective study setting and it should be followed by researchers in computer science and other professionals working in this kind of study validation.

Robert et al. recommend the use of serious games in Alzheimer patients' treatment, stimulation and rehabilitation with emphasis on creating game interfaces adapted to the users' capacities and interests. Additional strengths of gaming encompass less stress over assessment processes, real-time performance measurement and immediate feedback delivery accompanied with home-based skill practice. Interestingly, serious games introduce innovative ways for social bonding through games with multiple players physically co-present, or in groups. Moreover, real life simulation and control of stimuli facilitate rehabilitation purposes of dementia-related disorders. Future studies should focus on creating and implementing serious games, specifically targeting the aforementioned populations.

In the study of Redick et al. videogames as cognitive interventions are related to spatial imagery improvement, although the transfer effect on spatial ability is rather 
ambiguous due to small sample sizes and inappropriate experimental control procedures.

Oei et al. deal with the mechanism of transfer in action videogames (AVGs) training regimes. Perceptual and attentional skills acquired through repeated playing of a videogame need to be verified by a specific test, designed to measure the aforementioned cognitive skills. Furthermore, neuroimaging and working memory training literature also support specific over general transfer effects. Future research should focus on the specifity of the transfer effects through a quantifiable metric, hence, leading to adequate training of cognitive skills. The properties to be taken under consideration in an effective training session encompass, specifying on an exact set of cognitive skills as well as the latest' durability of transfer effects, regardless of subjects' individual differences.

Oei et al. investigated on the transfer effects in executive functioning as a result of a variety of video games training, during which complex planning, strategizing and reframing skills were on demand. Results showed that the puzzle video game with changing requirements improved executive functions, considering the large effect sizes for improvements between pre and post-training. Executing function improvements attained by respective skills were underdocumented.

Mc Dermott et al. study on the relation between memory and action video games. Action video game players' (AVGPs) weighting of speed contrary to accuracy was attributed to the different strategies selected by players in four multiple memory abilities tasks as substantial evidence on the long-term memory capacity improvement were insufficient. Nonetheless, speed of processing increased as well as visual short-term memory was enhanced, both related to the common action video game players' cognitive demands.

Boot et al. looked into the gamers' video game experience as a basic factor for improving attention, memory and executive functions. Although, habitual gamers (experts) outperformed non-gamers in various tasks, the improvement itself was rather insignificant. Researchers explained that the aforementioned result is related to the task features as they centred on accuracy over speed. Furthermore, improved performance in cognitive-related tasks is a complex issue, in which game-specific transfer effects demand respective game features and strategies.

Shawn Green et al. researched on action video gamers' task-switching skill. Three experiments took place in which, task-related goal, features and cognition aspects were measured. Action video gamers performed better than non-action video gamers in reducing the switch-cost between tasks as a result of their training. Although AVGs' reaction time, after training, was only marginally reduced, action video games gradually win grounds on the aspiring challenge of improving multi-media taskers' taskswitching abilities.

Akinlofa et al. showed that spatial navigational skills acquisition and mental representation tasks through gamebased experiences are interrelated issues under the provision of standardized task complexity as well as participant's spatial orientation ability.

Baniqued et al. deployed casual video games that were highly correlated with performance on working memory and reasoning tasks, including across-session adaptive games for studying on their effectiveness in improving cognition. Although young adults' divided attention skill was improved, transfer to other cognitive domains, such as working memory capacity or fluid intelligence was not observed. Overall, cognitive enhancement seems to be strongly related to individuals' being occupied with various and complex in strategy, reasoning games for developing their working memory function and eventually their problem solving and attention skills. Further research in the attentional control tasks may specify on the planning or reasoning abilities that can be observed while performing tasks that demand higher attention skills, thus advancing the transfer of real-life skills.

\section{ARTIFICIAL INTELLIGENCE}

According to Nicholson et al., the WOMBAT (Situational Awareness and Stress Tolerance Test) is an adaptive comprehensive computer-based assessment tool that allows for the prediction of real-world dynamic decisionmaking performances. More specifically, the WOMBAT integrates and measures firefighting personnel's working memory, visual attention and spatial reasoning skills, forming their situational awareness, thus predicting the transfer of their dynamic decision-making performance in a variety of operational settings and cognitive loads.

Montani et al. designed a trial-by-trial adaptive videogame, the "Labyrinth", aiming at the cognitive rehabilitation of brain-damaged patients. The adaptive algorithm maximizes the benefit of the training program, which captures patients' both attention and interest. The game's principles centre on participants' attention skill by deploying multi-tasking and task-switching stimuli. Validation research of the game verified of its capacity to stimulate subject's high levels of attention functions, related to control and flexibility.

Lamb et al. made use of the Serious Educational Games as part of students' science learning enhancement. The authors created a mode of cognitive assessment with an emphasis on complex cognitive processes through an Artificial Neural Network, leading to a specific set of tasks with the aim to address to students' individual cognitive needs. Furthermore, science curricula and Serious Game design could be refined in order, first, to acknowledge students' varied cognitive skills and second, to improve the latest's' learning effects.

Wetzel et al. present an adaptive model of play against a computational antagonist over a visuo-spatial strategy game. Novice player's psychophysical data, originating from his eye movements in addition to his strategies in the whole game are interpreted so as to maintain a satisfying behavior during play. Test participants experienced low levels of frustration and higher levels of fun on account of the fact that they were given a positive reinforcement through their antagonist' being able to adapt to their skill efficacy, thus evoking their personal improvement.

Azeem Abbas et al. adopted two mobile applications, the first for learning purposes and the second for evaluating young children's learning gains, originating from the aforementioned application. OntoCog, a knowledge model using artificial intelligence for specifying the vocabulary of terms and their semantics, enhances dynamic content creation by adding new information to respective user's previously stored interlinked contents. CogSkills targeted at the acquired cognitive skills upon implementation of the latest application and verified of its potential to build 
on pre-schoolers' classification, relatedness and memory skills.

Azeem Abbas et al. propose an intelligent tutoring system (ITS), called MySekolah, which uses knowledge representation for the creation of dynamic learning contents, both for practicing and evaluating child's cognitive skills, such as classification, relatedness, comparison (sequencing, discrimination, size etc.) and reasoning skills. Navigation among learning contents depends on the assessment results of the child's solutions. The aforementioned system was found consistent, efficient and effective in regards to its use and design purposes.

Lancheros-Cuesta et al. make a thorough analysis on the algorithms and techniques utilized in an adaptive elearning system of a course in order to enhance the learning process for students with mild cognitive disabilities or learning difficulties. The teacher could assign specific activities in content and information display to assist the particular learning process of these students, according to their respective disabilities, preferences, learning styles, performance in language, attention and memory aspects. Future research should be directed to the assessment of students' learning pace and performance in the process of prioritizing the adaptation variables for addressing diverse and mild cognitive disabilities.

Whent et al. initiate an online model that uses a data warehouse of relevant data sources in order to screen and thus, provide additional support towards students' cognitive development. The model compares children's performance in approximately 100 video games and in similar comparison groups, according to age, ethnic background, social background and learning or physical level. The data integration algorithm is constructed based on games data and children's cognitive data in the fields of auditory processing, visual processing, sequential/rational processing, conceptual/abstract processing, speed and executive functioning skills. Remediation could be centered on children's cognitive weaknesses in the form of playing more in-target games.

Mandiliotis et al. created an innovative humancomputer interaction (HCI) environment called Symbiosis, which consists of three interconnected modules with diverse functionalities either for the Patient, the Caregiver or the Doctor. The aforementioned system provides integrated solutions, forming a holistic approach to a series of problems related with Alzheimer by taking into account patients' needs for improvement in memory, attention, orientation, visual and space perception skills. In addition, patients' frequent monitoring and up to date information supply as well as caregivers' psychological support aim to facilitate professionals' work efficiency. Ultimately, personalization and multimodal interaction are the main characteristics of Symbiosis.

\section{RESEARCH HIGHLIGHTS \& CONCLUSIONS}

Current review article includes PC-based applications with the aim to assess and improve attention, working memory and executive functions as well as reading comprehension, critical thinking and meta-cognitive skills. The target group of the aforementioned interventions is mainly children with learning disabilities (Attention Deficit Hyperactivity Disorder or Specific Language Impairment) and elderly people.
Video games' specific transfer effects are extensively discussed in this review as their measurement or durability in real-life contexts is still questioned. More specifically, attention, perception, memory and executive functions and their relation to video games are under examination, aimed to address the needs of rehabilitation programs for people with dementia or children with Attention Deficit Hyperactivity Disorder (ADHD).

Artificial intelligence-based rehabilitation and training programs leverage individuals' cognitive skills, such as attention, memory, classification, relatedness, comparison and reasoning skills largely through their adaptability and personalization features. Users' motivation and interest originate from the fact that the tasks or games provided are cognitively stimulating and demand strategic thinking as well as they adapt to users' psychological data.

Mobiles are outperformed by tablets in the field of cognitive assessment for the elderly, whereas in the reading comprehension process, text scrolling speeds were found significant for mobile active reading.

Web-based application, such as students' high level cognitive processing tasks, concept-mapping tools and scaffoldings are some cognitive interventions leading to learning gains, whereas videoconferences and online modules serve as demented patients' cognitive stimulants.

Therefore, ICTs implementation in the assessment and treatment of cognitive skills is attributed to the formers' usefulness, flexibility and users' perceived stimulation, mainly through their adaptable and personalized features. Attention, memory and executive functions are supported by interactive, collaborating and immersive applications, especially video games in conjunction with artificial intelligence. Artificial intelligence either in video games, mobiles or other pc-based systems, improve users' learning potential or treatment progress through motivating and realistic experiences as well as through integrative information processes. Finally, ICTs offer their assistance to caregivers, educators and medical staff and do not substitute them as the former enhance communication and interactivity, thus promoting holistic and cost-effective interventions.

\section{REFERENCES}

[1] Drigas, A. and Dourou, A.: "A review on ICT based applications for intervention and assistance of people with memory-deficits", iJET, vol. 8, issue 5, pp. 47-49, (2013).

[2] Howard-Jones, P. Ott, M. Van Leeuwen, T. and De Smedt, B.: "The potential relevance of cognitive neuroscience for the development and use of technology-enhanced learning", Learning, Media and Technology, pp. 1-21, (2014).

[3] Weng, P.L. Maeda, Y. and Bouck, E. C.: "Effectiveness of Cognitive Skills-Based Computer-Assisted Instruction for Students With Disabilities: A Synthesis", Remedial and Special Education, pp. 114, (2014).

[4] Fletcher-Watson S.: "A Targeted Review of Computer-Assisted Learning for People with Autism Spectrum Disorder: Towards a Consistent Methodology", Rev J Autism Dev Disord, vol.1, pp.87-100, (2014). http://dx.doi.org/10.1007/s40489-013-0003-4

[5] Aresti-Bartolome, N. and Garcia-Zapirain, B.: "Technologies as Support Tools for Persons with Autistic Spectrum Disorder: A Systematic Review", International Journal of Environmental Research and Public Health", vol. 11, pp. 7767-7802, (2014). http://dx.doi.org/10.3390/ijerph110807767

[6] Siberski, J. Shatil, E. Siberski, C. Eckroth-Bucher, M. French, A. Horton, S. Loefflad, R. F. and Rouse, P.: "Computer-Based Cognitive Training for Individuals With Intellectual and Developmen- 
tal Disabilities: Pilot Study", American Journal of Alzheimer's Disease \& Other Dementias, pp. 1-8, (2014).

[7] Singh, M. and Narang, M.: "Cognitive enhancement Techniques", IJITKM, vol. 7, number 2, pp. 49-61, (2014).

[8] Lauriks, S. Reinersmann, A. Geralde van der Roest, H. Meiland, F. Davies, R. Moelaert, F. Mulvenna, M. D. Nugent, C. D. and Dröes, R.-M.: "Review of ICT-Based Services for Identified Unmet Needs in People with Dementia" in M.D. Mulvenna, C.D. Nugent (eds.), Supporting People with Dementia Using 37 Pervasive Health Technologies, Advanced Information and Knowledge Processing, pp. 37-61, Springer-Verlag London Limited 2010. http://dx.doi.org/10.1007/978-1-84882-551-2 4

[9] Koldrack, P. Luplow, M. Kirste, T. and Teipel, S.: "Cognitive assistance to support social integration in Alzheimer's disease", Geriatric Mental Health Care, vol. 1, pp. 39-45, (2013). http://dx.doi.org/10.1016/j.gmhc.2013.04.005

[10] Gabriele, L. Tavernise, A. and Bertacchini, F.: "Active learning in a robotics laboratory with university students" in Increasing Student Engagement and Retention using Immersive Interfaces: Virtual Worlds, Gaming, and Simulation, Cutting-edge Technologies in Higher Education, Vol. 6C, pp. 315-339, (2012). http://dx.doi.org/10.1108/S2044-9968(2012)000006C014

[11] Packiam Alloway, T. and Stein,A.: "Investigating the link between cognitive skills and learning in non-comorbid samples of ADHD and SLI", International Journal of Educational Research, vol. 64, pp. 26-31, (2014). http://dx.doi.org/10.1016/j.ijer.2013.10.003

[12] Vugs, B. Hendriks, M. Cuperus, J. and Verhoeven, L.: "Working memory performance and executive function behaviors in young children with SLI", Research in Developmental Disabilities, vol. 35, pp. 62-74, (2014). http://dx.doi.org/10.1016/j.ridd.2013.10.022

[13] Rute-Pérez, S. Santiago-Ramajo, S. Visitación Hurtado, M. Rodríguez-Fórtiz, M. J. and Caracuel, A.: "Challenges in software applications for the cognitive evaluation and stimulation of the elderly", Journal of NeuroEngineering and Rehabilitation, vol. 11, number 88, pp. 1-10. (2014).

[14] Johnson, T. E. Archibald, T. N. and Tenenbaum, G.: "Individual and team annotation effects on students' reading comprehension, critical thinking, and meta-cognitive skills", Computers in Human Behavior, vol. 26, pp. 1496-1507, (2010). http://dx.doi.org/10.1016/j.chb.2010.05.014

[15] Demiris, G. Thompson, H. J. Reeder, B. Wilamowska, K. and Zaslavsky, O.: "Using informatics to capture older adults' wellness", International Journal of Medical Informatics, vol. 8, number 2, pp. 232-241, (2013).

[16] Rocha Dores, A. Palmares Carvalho, I. Barbosa, F. Almeida, I. Guerreiro, S. Oliveira, B. De Sousa, L. and Castro Caldas, A.: "Computer-Assisted Rehabilitation Program - Virtual Reality (CARP-VR): A Program for Cognitive Rehabilitation of Executive Dysfunction" in G.D. Putnik and M.M. Cruz-Cunha (Eds.): ViNOrg 2011, CCIS 248, pp. 90-100, (2012).

[17] Lee, R. R.-W. Sung, Y.-T. and Chang, K.-E.: “ Game-induced learning Effect: A Cognitive Neuroscience perspective", International Conference on Information, Business and Education Technology (ICIBIT 2013).

[18] Lee, S. Baik, Y. Nam, K. Ahn, J. Lee, Y. Oh, S. Kim, K.: "Developing a cognitive evaluation method for serious game engineers", Cluster Comput, vol. 17, pp. 757-766, (2014). http://dx.doi.org/10.1007/s10586-013-0289-0

[19] Frutos-Pascual, M. Zapirain, B. G. and Buldian, K. C.: "Adaptive Cognitive Rehabilitation Interventions based on Serious Games for Children with ADHD using Biofeedback Techniques: Assessment and Evaluation", Author's Guide to Preparing ACM SIG Proceedings.

[20] Robert P. H. König, A. Amieva, H. Andrieu, S. Bremond, F. Bullock, R. Ceccaldi, M. Dubois, B. Gauthier, S. Kenigsberg, P.A. Nave, S. Orgogozo, J.M. Piano, J. Benoit, M. Touchon, J. Vellas, B. Yesavage J. and Manera, V.: " Recommendations for the use of Serious Games in people with Alzheimer's Disease, related disorders and frailty", Frontiers in Aging Neuroscience, vol. 6, article 54, pp. 1-13, (2014).

[21] Redick, T. S. and Webster, S. B.: "Videogame interventions and spatial ability interactions", Frontiers in Human Neuroscience, vol. 8 , article 183 , pp. $1-5,(2014)$.
[22] Oei, A. C. and Patterson, M. D.: "Are videogame training gains specific or general?", Frontiers in Systems Neuroscience, vol. 8, article 54, pp. 1-9, (2014).

[23] Oei, A. C. and Patterson, M. D.: "Playing a puzzle video game with changing requirements improves executive functions", Computers in Human Behaviour, vol. 37, pp. 216-228, (2014). http://dx.doi.org/10.1016/j.chb.2014.04.046

[24] Montani, V. De Filippo De Grazia, M. and Zorzi, M.: “A new adaptive videogame for training attention and executive functions: design principles and initial validation", Frontiers in Psychology, vol. 5, article 409, pp. 1-12, (2014).

[25] Nicholson, B. and O'Hare, D.: "The effects of individual differences, prior experience and cognitive load on the transfer of dynamic decision making performance", Ergonomics, vol. 57, number 9, pp. 1353-1365, (2014).

[26] Mc Dermott, A. F. Bavelier, D. and Shawn Green, C.: "Memory abilities in action video game players", Computers in Human Behavior, vol. 34, pp. 69-78, (2014). http://dx.doi.org/10.1016/j.chb.2014.01.018

[27] Boot, W. R. Kramer, A. F. Simons, D. J. Fabiani, M. and Gratton, G.: "The effects of video game playing on attention, memory, and executive control", Acta Psychologica, vol. 129, pp. 387-398, (2008). http://dx.doi.org/10.1016/j.actpsy.2008.09.005

[28] Shawn Green, C. Sugarman, M.A. Medford, K. Klobusicky, E. and Bavelier, D.: "The effect of action video game experience on task-switching", Computers in Human Behavior, vol.28, pp. 984994, (2012). http://dx.doi.org/10.1016/j.chb.2011.12.020

[29] Lamb, R. L. Annetta, L. Vallett, D. B. and Sadler, T. D.: “Cognitive diagnostic like approaches using neural-network analysis of serious educational videogames", Computers \& Education, vol. 70, pp. 92-104, (2014). http://dx.doi.org/10.1016/j.compedu. 2013.08.008

[30] Akinlofa, O. R. O'brian Holt, P. and Elyan, E.: "The cognitive benefits of dynamic representations in the acquisition of spatial navigation skills", Computers in Human Behavior, vol. 30, pp. 238-248, (2014). http://dx.doi.org/10.1016/j.chb.2013.09.009

[31] Baniqued, P. L. Kranz, M. B. Voss, M. W. Lee, H. Cosman, J. D. Severson, J. and Kramer, A. F.: "Cognitive training with casual video games: points to consider", Frontiers in Psychology, vol. 4, article 1010, pp. 1-19, (2014).

[32] Wetzel, S. Spiel, K. and Bertel, S.: "Dynamically Adapting an AI Game Engine Based on Players' Eye Movements and Strategies", EICS'14, June 17 - 20 2014, Rome, Italy.

[33] Azeem Abbas, M. Wan Ahmad, W. F. and Kalid, K. S.: "OntoCog: A Knowledge Based Approach for Preschool Cognitive Skills Learning Application", Procedia - Social and Behavioral Sciences, vol. 129, pp. 460 - 468, (2014).

[34] Azeem Abbas, M. Wan Ahmad, W. F. and Kalid, K. S.: "Semantic Web Technologies for Pre-School Cognitive Skills Tutoring System", Journal of Information Science and Engineering, vol. 30, pp. 835-851, (2014).

[35] Lancheros-Cuesta, D. J. Carrillo-Ramos, A. and Pavlich-Mariscal, J. A.: "Content adaptation for students with learning difficulties: design and case study", International Journal of Web Information Systems, vol. 10, number 2, pp. 106-130, (2014). http://dx.doi.org/10.1108/IJWIS-12-2013-0040

[36] Whent, R. Martinovic, D. Ezeife, C. I. Ahmed, S. Alahmad, Y. and Mumu, T.: "School age children's cognition identification by mining integrated computer games data", CSEDU 2012 - 4th International Conference on Computer Supported Education, pp. 495-505.

[37] Mandiliotis, D. Toumpas, K. Kyprioti, K. Kaza, K. Barroso, J. and Hadjileontiadis, L. J.: "Symbiosis: An Innovative HumanComputer Interaction Environment for Alzheimer's Support", C. Stephanidis and M. Antona (Eds.): UAHCI/HCII 2013, Part II, LNCS 8010, pp. 123-132, (2013).

[38] Chen, C.-M. and Lin, Y.-J.: "Effects of different text display types on reading comprehension, sustained attention and cognitive load in mobile reading contexts", Interactive Learning Environments, pp.1-19, (2014). http://dx.doi.org/10.1080/10494820.2014.891526

[39] Brouillette, R. M. Foil, H. Fontenot, S. Correro, A. Allen, R. Martin, C. K. Bruce-Keller, A. J. Keller, J. N.: "Feasibility, Reliability, and Validity of a Smartphone Based Application for the As- 
PAPER

ONLINE AND OTHER ICT APPLICATIONS FOR COGNITIVE TRAINING AND ASSESSMENT

sessment of Cognitive Function in the Elderly", PLOS ONE, vol. 8 , issue 6, pp. 1-5, (2013).

[40] Petchtone, P. and Sumalee, C.: "The validation of web-based learning environment model to enhance cognitive skills and critical thinking for undergraduate students", Procedia - Social and Behavioral Sciences, vol. 116, pp. $669-673,(2014)$.

[41] Lin, P.-C. Hou, H.-T. Wu, S.-Y. and Chang, K.-E.: "Exploring college students' cognitive processing patterns during a collaborative problem-solving teaching activity integrating Facebook discussion and simulation tools", Internet and Higher Education, vol. 22, pp. 51-56, (2014). http://dx.doi.org/10.1016/j.iheduc.2014. 05.001

[42] Howard-Jones, P. Holmes, W. Demetriou, S. Jones, C. Tanimoto, E. Morgan, O. Perkins, D. and Davies, N.: "Neuroeducational research in the design and use of a learning technology", Learning, Media and Technology, (2014).

[43] Jelcic, N. Agostini, M. Meneghello, F. Bussè, C. Parise, S. Galano, A. Tonin, P. Dam, M. and Cagnin, A.: "Feasibility and efficacy of cognitive telerehabilitation in early Alzheimer's disease: a pilot study", Clinical Interventions in Aging, vol. 9, pp. 16051611, (2014).

[44] Lindsay James Riegler, L. J. Neils-Strunjas, J. Boyce, S. Wade, S. L. Scheifele, P. M.: "Cognitive intervention results in web-based videophone treatment adherence and improved cognitive scores",
Medical Science Monitor, vol. 19, pp. 269-275, (2013). http://dx.doi.org/10.12659/MSM.883885

[45] Curcic, S. : "Addressing the needs of students with learning disabilities during their interaction with the web", Multicultural Education \& Technology Journal, vol. 5, Number 2, pp. 151-170, (2011). http://dx.doi.org/10.1108/17504971111142673

[46] Campbell, T. Kwei Wang, S. Hsu, H.-Y. Duffy, A. M. Wolf, P. G.: "Learning with Web Tools, Simulations, and Other Technologies in Science Classrooms", J Sci Educ Technol, vol. 19, pp. 505-511, (2010). http://dx.doi.org/10.1007/s10956-010-9217-8

\section{AUTHORS}

A. Drigas is with N.C.S.R. 'Demokritos', Institute of Informatics and Telecommunications, Telecoms Lab - Net Media Lab, Agia Paraskevi, 153 10, Athens, Greece ( email: dr@iit.demokritos.gr)

M. Karyotaki is with N.C.S.R. 'Demokritos', Institute of Informatics and Telecommunications, Telecoms Lab Net Media Lab, Agia Paraskevi, 153 10, Athens, Greece (e-mail: karyotakimaria@gmail.com)

Submitted 30 December 2014. Published as resubmitted by the authors 10 March 2015. 